\title{
Is Virtual Reality Safety Training Making the Construction Industry Safer?
}

\author{
Jason B. Manning ${ }^{1}$, Junshan Liư ${ }^{2}$ and Lauren Redden ${ }^{3}$ \\ 1 Auburn University, Auburn, USA, jbm0086@auburn.edu \\ 2 Auburn University, Auburn, USA, liujuns@auburn.edu \\ 3 Auburn University, Auburn, USA, wybenIm@auburn.edu
}

\begin{abstract}
The construction industry by nature is an unsafe environment to work in. It's a large industry that employs a lot of people and unfortunately experiences a large number of accident's each year. Construction companies invest a lot of money in safety training trying to educate their work forces. The primary types of training are instructor led, through training manuals and hands on. $80 \%$ of accidents happen due to human error. This statistic shows the conventional ways of training need improvements. Virtual Reality's popularity has exploded over the last decade and its use in the construction industry has increased mainly due to the use of 3D modeling for construction designs. Construction companies have also started using it as a safety training tool. It provides the ability to put a worker in an unsafe situation virtually for them to think through the process and come up with a solution. This paper is intended to review the research that has already been conducted on the topic of virtual reality use in the construction safety training industry. It will also perform a survey of construction contractors to determine if they have used or are planning to us virtual reality safety training.
\end{abstract}

(c) 2020 The Authors. Published by Budapest University of Technology and Economics \& Diamond Congress Ltd Peer-review under responsibility of the Scientific Committee of the Creative Construction Conference 2020.

Keywords: Virtual Reality, VR, BIM, 3D modeling, construction safety, training

\section{Introduction and background}

In 2017 there were 4,674 worker fatalities within the private sector in the United States of America, the construction industry was responsible for 971 deaths, which is $20.7 \%$ ("Home | Occupational Safety and Health Administration," n.d.). The construction industry employees about $5 \%$ of workers (Writer, n.d.). Of the many reasons an accident can happen up to $80 \%$ are caused by human error (Garrett \& Teizer, 2009). This is usually caused by lack of safety measures, training and lack of safety awareness ( $\mathrm{Li}, \mathrm{Yi}, \mathrm{Chi}$, Wang, \& Chan, 2018). Safety training is one of the most effective ways to prevent accidents (Bin, Xi, Yi, \& Ping, 2019). Anyone who has been through traditional safety training knows that it is viewed as more of a chore or inconvenience to the worker and its just a box that needs to be checked. This is due to the traditional training methods that cannot produce an immersive training environment (Bin et al., 2019).

Virtual Reality (VR) technologies and trainings have been developed to help provide a more immersive training, placing the user in a virtual environment that can mimic real situations. VR has been used to train pilots, put military members in combat situations, surgeons and test manufacturing methods (Bhoir \& Esmaeili, 2015a). Recently companies have been developing construction safety specific training for subjects like trench safety, fall protection, working from heights, welding and lock out tag out operations (pixo2019, n.d.). VR training is designed to keep the participants interest through the entire training resulting in a higher retention of the safety material. 
This paper is intended to review the research that has already been conducted on the topic of virtual reality use in the construction safety training industry. It will also perform a survey of construction contractors to determine if they have used or are planning to us virtual reality safety training. It will also survey roofing contractors to see if they have incorporated VR in their training regime.

\subsection{History of Virtual Reality}

Virtual Reality (VR) has been in development for over 100 years. The concept of virtual reality is "creating the illusion that we are present somewhere that we are not" ("History Of Virtual Reality," n.d.), then the beginning of the concept can be traced back early nineteenth century with panoramic paintings. Then throughout the late nineteenth and early twentieth century the stereoscopic viewer was created. This placed the same photo side by side in the viewer and the eyes would view the photos as a three-dimensional photo creating depth. Around this same time Edward Link created the first flight simulator called the Link trainer, which was patented in 1931. It was developed to safely train pilots and during World War II, 10,000 Link Trainers were used to train 500,000 pilots ("History Of Virtual Reality," n.d.). Also, in the 1930's a science fiction movie, named Pygmalion's Spectacles, about a pair of goggles that led the user to a fictitious world. Then in the 1950's Morton Heilig created Sensorama, which was a theater cabinet that provided stimulation to the eyes, ears, nose and touch through screens, speakers, smell generators and vibrators.

The first head mounted VR display was created in 1965, this allowed the user to view a video screen with each eye and incorporated a motion tracking system that was hooked up to a camera. Modern day virtual reality headsets were developed in 1987, by Jaron Lanier, called the EyePhone ("History Of Virtual Reality," n.d.). He also created the Dataglove to stimulate feel ("History Of Virtual Reality," n.d.). In the 1990's video games were created using virtual reality technology. At first the technology was expensive, so these games were only offered in video arcades. Sega created a prototype for what was thought to be the first mass produced VR headset and promoted it at the Consumer electronics show in 1993. This headset included speakers and LCD screens. Unfortunately, the headset was never finished. Nintendo also tried its hand created a household VR gaming system. Due to its lack of colors and difficulty of use it never took off and was discontinued after only one year ("History Of Virtual Reality," n.d.).

In 1999 the movie trilogy The Matrix was released. Although not the first film to depict a virtual reality world, it was the first that appealed to the mainstream public. In the twenty first century virtual reality development has soared especially with the fast advancement of computer and smart phone technologies. Also the video game industry is driving the technology, with systems like PlayStation and Xbox coming out with their own VR headsets and game controllers. Tech giants Facebook, Google and Samsung have either developed their own VR headsets or have bought virtual reality technology companies ("History Of Virtual Reality," n.d.).

\subsection{Construction safety}

The construction industry is a dangerous work environment with complex project sites and uneducated workers (Pedro, Le, \& Park, 2016). Over the last two hundred years there has been major advancements in construction safety and workers' rights, but still the industry employs $5 \%$ of all workers and is responsible for $17 \%$ of workplace accidents (Writer, n.d.)

During the early 1800's safety in the construction industry was nonexistent. After the civil war workers began buying insurance incase of a job-related injury. Some employers began providing insurance and started paying higher wages, due to workers leaving high risk positions.

In the 1900s commissions began to form protecting construction workers, but unfortunately, they had little power and provided little benefit. New York was the first state to pass a worker's compensation law to dictate a fixed rate that employers would pay for injured workers. Then in 1913 the National Safety Council and the U.S. Department of labor was founded. These federal organizations promoted and focused on safe workplaces. In 1916 the Federal Compensation Act was established mandating benefits for workers who were injured or caught illnesses while working on the job. Within 5 years 44 states had adopted similar laws (Writer, n.d.). 
Probably the most significant development in construction safety was the establishment of the Occupational and Health Act, which created the Occupational Safety and Health Administration (Writer, n.d.). OSHA's main goal is to oversee and enforce safe working conditions for workers by setting standards and providing training ("About OSHA | Occupational Safety and Health Administration," n.d.). They developed the 1926 construction safety manual that sets the minimum standards for construction job site safety. The Department of Defense developed the EM 385 which meets or exceeds OSHA's manual and is the manual in which safety regulations are enforced on government construction sites. With all this development in construction safety over the years, the industry lost 971 workers in 2017 ("Home I Occupational Safety and Health Administration," n.d.).

\subsection{VR in construction}

People learn in many different ways. Some people are auditory learners and prefer to listen to lectures than read note. Some are kinesthetic learners where they like to act out events to reinforce the information. Visual learners prefer seeing the information in diagrams, pictures or words. Lastly there are reading/writing learners who prefer their learning to be in the form of the written word. It is important to train workers in many ways to cater to every learning type (Bhoir \& Esmaeili, 2015a). Virtual reality training has been introduced into the construction training sector for many reasons including its ability to recreate dangerous situations without being on a jobsite. It also allows students to train at their own pace, it is not weather dependent and can be conducted at any time (Bhoir \& Esmaeili, 2015a). With this type of training workers assess dangerous situations, choose a course of action, and implement that action and see the results (Sacks, Perlman, \& Barak, 2013). Virtual reality safety trainings have been developed for many different construction activities and benefits, see table 1(Bhoir \& Esmaeili, 2015a).

Table 1 . Summary of virtual reality applications in construction safety

\begin{tabular}{|c|c|c|}
\hline & Purpose & Benefits/Contributions \\
\hline Squelch (2001) & $\begin{array}{l}\text { Developing a training simulator } \\
\text { for identifying fall of ground } \\
\text { hazards in mining industry. }\end{array}$ & $\begin{array}{l}\text { Creating an effective medium for illiterate } \\
\text { workers in the mining industry to identify } \\
\text { hazards. }\end{array}$ \\
\hline $\begin{array}{l}\text { Hadikusumo and } \\
\text { Rowlinson (2004) }\end{array}$ & $\begin{array}{l}\text { Developing a design for safety } \\
\text { (DFSP) tool. }\end{array}$ & $\begin{array}{l}\text { Capturing the tacit safety knowledge from } \\
\text { safety engineers about construction safety } \\
\text { hazards and precautions. }\end{array}$ \\
\hline $\begin{array}{l}\text { Chantawit et al. } \\
(2005)\end{array}$ & $\begin{array}{l}\text { Developing a platform to } \\
\text { integrate } 3 \mathrm{D} \text { models and safety } \\
\text { concerns with a project } \\
\text { schedule. }\end{array}$ & $\begin{array}{l}\text { Enabling users to analyze construction } \\
\text { sequence, measure spatial and temporal } \\
\text { interactions, and monitor safety measures } \\
\text { that are required to cany out specific } \\
\text { works according to a project schedule. }\end{array}$ \\
\hline Zhao et al. (2009) & $\begin{array}{l}\text { Developing an electrical safety } \\
\text { training program to enhance } \\
\text { workers' awareness. }\end{array}$ & $\begin{array}{l}\text { Developing several training modules } \\
\text { allows sorting relevant hazards and } \\
\text { scenarios to prevent overloading a user } \\
\text { with information. }\end{array}$ \\
\hline $\begin{array}{l}\text { Dickinson et al. } \\
\text { (2011) }\end{array}$ & $\begin{array}{l}\text { Developing a serious game for } \\
\text { trench safety education. }\end{array}$ & $\begin{array}{l}\text { Engaging students and providing an } \\
\text { innovative medium for hands-on activities. }\end{array}$ \\
\hline $\begin{array}{l}\text { Guo et al. (2012), } \\
\text { Li et al. (2012) }\end{array}$ & $\begin{array}{l}\text { Developing a multiuser virtual } \\
\text { safety training system for } \\
\text { construction plant operations. }\end{array}$ & $\begin{array}{l}\text { Developing an easy multi-user virtual } \\
\text { environment that allows trainees to } \\
\text { collaborate with each other. }\end{array}$ \\
\hline $\begin{array}{l}\text { Park and Kim } \\
\text { (2013) }\end{array}$ & $\begin{array}{l}\text { Developing a framework to } \\
\text { integrate Building Information } \\
\text { Modeling (BIM) and location } \\
\text { tracking, augmented realty, and } \\
\text { game technologies. }\end{array}$ & $\begin{array}{l}\text { Enhancing hazard identification and real- } \\
\text { time communication between construction } \\
\text { managers and workers. }\end{array}$ \\
\hline Fang et al. (2014) & $\begin{array}{l}\text { Developing a framework to } \\
\text { integrate Building Information } \\
\text { Modeling (BIM) and real-time } \\
\text { location tracking technology in } \\
\text { a virtual environment }\end{array}$ & $\begin{array}{l}\text { Developing a close to real experience for } \\
\text { training crane operators by simulating the } \\
\text { as-built work scenarios. }\end{array}$ \\
\hline
\end{tabular}

\section{Literature review}

Virtual reality is a fairly new technology being utilized in the construction industry. It is mainly used in combination with 3D modeling to give stakeholders the ability to virtually walk through buildings to get a 
feel for the space and layout. Recently it has been used by the construction safety industry as a safety training tool. Since it is fairly new to the construction safety industry not a lot of research has been conducted on if it is making the construction industry safer. Most of the research done is the utilization and functionality of VR for construction safety. Figure-1 shows the number of paper s published per year from 2000-2017. With that said Sneda Bhoir and Behzad Esmaeili conducted research on the use of VR as a safety training tool. Their research, conducted in 2015, determined that it was being used by $0 \%$ of their survey responding contractors. They made the conclusion computer knowledge among construction workers is usually low. Contractors also did not have the specialized experience needed to change or modify virtual environments (Bhoir \& Esmaeili, 2015a). Their research also revealed that only 7\% of respondents indicated they may try VR technology within the next 2 years.

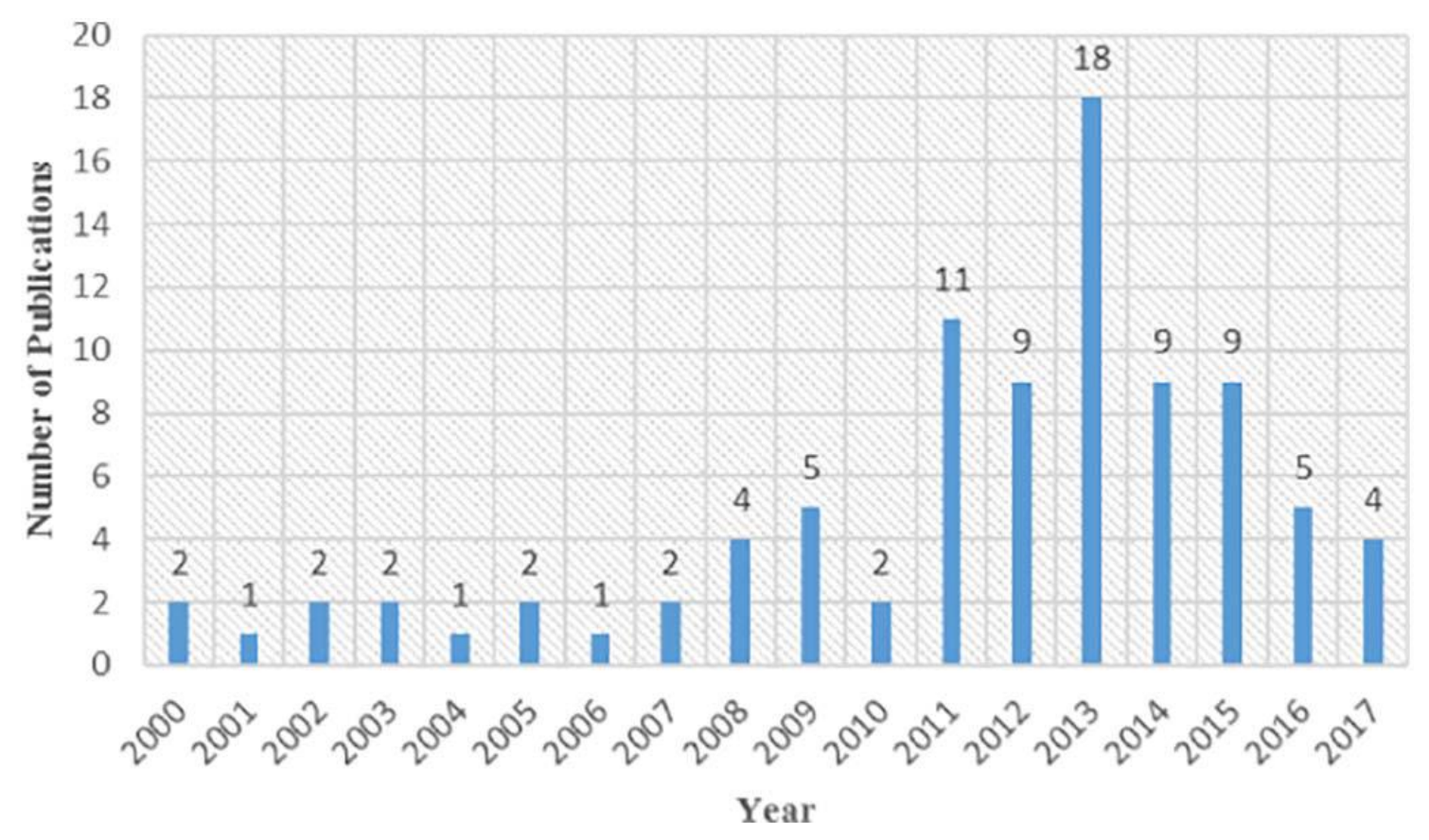

Fig. 1. Number of papers published per year on utilization and functionality of VR for construction safety (Li, Yi, Chi, Wang, \& Chan, 2018)

\section{Research methodology, results and analysis}

\subsection{Research Methodology}

Research conducted for this paper was mostly reviewing prior studies and telephone surveys. As noted before Sneda Bhoir and Behzad Esmaeili, conducted research in 2015 which concluded, 0\% of responding contractors were using VR as a training tool and only 7\% plan on using it in the next few years. Those contractors were mostly using more conventional training tools like instructor led and hands on training. The breakdown of the training types from Bhoir and Esmaeili research are shown in table 2, below.

Table 2 Construction Safety Training Methods

\begin{tabular}{clcclc}
\hline$\#$ & Training methods & Percentage used & $\#$ & Training methods & Percentage used \\
\hline 1 & Instructor led & $100 \%$ & 5 & Computer based & $50 \%$ \\
2 & Training manuals & $93 \%$ & 6 & Game based & $29 \%$ \\
3 & Audio/visual & $86 \%$ & 7 & Workshops & $21 \%$ \\
4 & Hands on & $79 \%$ & 8 & Virtual reality & $0 \%$ \\
\hline
\end{tabular}

Telephone surveys were also conducted for this paper. The researcher first started to call general contractors from Engineering and Record (ENR) top 400 contractors list. He quickly realized the top companies are very large and finding the right person to speak with was very difficult. He then tried calling federal contractors that were working on Camp Lejeune and Fort Bragg, the two nearest military facilities. These construction companies are also large but connecting with the right safety person to survey was 
much easier. In total 12 construction companies were called 4 were actively using VR technology for construction safety training, 2 were not using safety training but did indicate that they had planned to in the next few years, and 6 responded that they did not plan on using this technology in the near future. Below are the survey questions used for this research.

1. Does your company currently use virtual reality as a safety training measure? If not why not?

2. If so what topics does the virtual reality training cover? (ie. fall protection, trenching, leading edge, welding)

3. Do you think that it helps keep the attention of your trainees better?

4. Do you think it helps with retention of the safety material?

5. Have you seen a difference in the amount of accidents your company has after including VR in your training?

6. What was your EMR before you starting using virtual reality? What is your current EMR?

7. What is the biggest advantage in using VR for construction safety training?

8. What needs to be improved to make VR a better training tool?

9. Are you planning to expand the use of VR in your training program? If so how?

If the company responded "no" to question 1, the follow-up questions are:

1. What training methods do you currently employ?

2. Do you plan to introduce VR into your training program?

3. Why has VR not been utilized up to his point?

4. Do you plan to introduce it within the next 2 years?

\subsection{Survey results and analysis}

\subsubsection{Companies using VR technology}

Of the companies surveyed 33\% were currently using VR technology which is large increase from the response that Bhoir and Esmaeili received in 2015. Of the topics that they cover in their VR training all responded they use it for fall protection. One company used it for trench safety and two companies used VR for crane signaling, which was a use the researcher had not read about while conducting the literature research. All companies thought the VR training kept the attention of the trainees better and helped with the retention of the material. Most companies have teamed up with training developer to receive new and updated trainings on a regular basis. MindForge is a company that many of the contractors used that develops VR safety training scenarios.

One thing every contractor that uses the VR technology has in common is their dedication to safety. All these companies have very low EMR rates and have not seen a difference since starting to use VR technology because their rates have always been low. Therefore, they all answered that they have not seen a difference in their EMR rates. The advantages the contractors answered were being able to put personnel in dangerous scenario without being in a dangerous situation. They also answered that it engaged the trainees and made them process a situation, identify the problem and work through the solution. VR being a new technology has a lot of room for improvement. The improvements that contractors identified were the need for more content, VR becoming more portable and making the technology easier to set up on job sites. They all also plan on expanding their use of VR training with more content. 


\subsubsection{Companies that do not use VR}

Eight of the twelve companies surveyed indicated that they did not currently use VR as a training tool. Two companies were using VR in conjunction with their 3D modeling for building walk throughs. Four companies did not know VR was being used for construction safety, which was surprising. The training methods used by these companies were OSHA 30 hour class, role playing, hands on and some used $3^{\text {rd }}$ party training companies. Two companies indicated that they planned to try VR as a training tool in the next two years. Two companies stated they did not use VR because they did not think it was a better training tool then what they were doing now. They also said what they used was working so they had no reason to change their safety training strategy.

\subsection{Survey conclusion}

The survey results show that there is an increased use of VR technology for construction safety training. The companies using the training appear to be ones that safety is their number one priority and they are always looking for ways to expand on their safety culture and training. The companies that have begun using VR are all in and think the technology is very useful and plan to expand their use over the next few years.

Two companies indicated they plan to use VR technology over the next two years. They had not use it to this point because they had not heard or learned much about it. One company actually said the researcher had convinced them to try it. Both companies have a low EMR and are always willing to try new measures to train its employees. Both companies were using the VR technology already for 3D modeling walkthroughs of buildings, so the company in general incorporates and uses new and emerging technology.

Six companies do not plan to use the VR technology in the near future. This was due to being satisfied with their current training measures, that in their opinion worked, so not need to change it. They also indicated they can replicate the training scenarios onsite without the use of headsets. The companies that used third party training companies said VR was no something that was offered and if it was, they would be willing to try it, but had not heard that it would be offered in the future.

\section{Conclusion and future research}

Although the concept of virtual reality has been around for many years, its only recently that the technology has advanced enough for it to move from the video game world into business. The use of BIM and 3D modeling in construction introduced VR to the construction industry. Since then it has started to be used for construction safety training. Being a newer technology there has been limited research focused on its use in the construction safety industry. Most of the research to date appears to be focused on the technology itself and functionality of it. Bhoir and Esmaeili have conducted the only research found that focuses on it actual use by contractors. Their research was performed in 2015, since that time the virtual reality technology has advanced and so have construction companies use. Although not widely accepted as a standard training tool it is rowing in use and with that the available content is growing as well. Innovative and safety conscious companies seem to be the first that are trying out this technology. They have low EMR rates and are always looking for new training measures to keep their employees sharp. The research conducted in this paper shows that 33\% of companies surveyed used VR and this is up form $0 \%$, from Bhoir and Esmaeili's research. It is however inconclusive on if it's making the industry safer. The companies surveyed do not have data that would either support or not support if VR is making the industry safer.

The future seems bright for the virtual reality industry. The technology is advancing all the time, which is increasing its usage. The research in this paper shows a 33\% increase in use from 2015's research. A similar research should be performed in 3-4 years to see if the usage is still increasing and at what rate. Also, research should be performed on what topics the companies are using VR training.

At the beginning of this research it was difficult to survey the large global contractors, due to not being connected with the right people. Some companies also refused to be a part of research of any kind. A good way to really survey construction contractors is to do it at a construction safety conference, where you have 
a large amount of safety professionals together. Also giving a demonstration of the VR technology and its use for construction safety then survey the conference about who plans to try and use it in the next two years.

\section{References}

[1] Bhoir, S., \& Esmaeili, B. (2015). State-of-the-Art Review of Virtual Reality Environment Applications in Construction Safety. AEI 2015, 457-468. https://doi.org/10.1061/9780784479070.040

[2] Bin, F., Xi, Z., Yi, C., \& Ping, W. G. (2019). Construction safety education system based on virtual reality. IOP Conference Series: Materials Science and Engineering, 563, 042011. https://doi.org/10.1088/1757-899X/563/4/042011

[3] Garrett, J. W., \& Teizer, J. (2009). Human Factors Analysis Classification System Relating to Human Error Awareness Taxonomy in Construction Safety. Journal of Construction Engineering and Management, 135(8), 754-763. https://doi.org/10.1061/(ASCE)CO.1943-7862.0000034

[4] History Of Virtual Reality. (n.d.). Retrieved November 25, 2019, from Virtual Reality Society website: https://www.vrs.org.uk/virtualreality/history.html

[5] Home | Occupational Safety and Health Administration. (n.d.). Retrieved November 25, 2019, from https://www.osha.gov/

[6] Li, X., Yi, W., Chi, H.-L., Wang, X., \& Chan, A. P. C. (2018). A critical review of virtual and augmented reality (VR/AR) applications in construction safety. Automation in Construction, 86, 150-162. https://doi.org/10.1016/j.autcon.2017.11.003

[7] MindForge Signal Person Training Virtual Reality. (n.d.). Retrieved from https://www.youtube.com/watch?v=EoBDs0WO2-0

[8] Pedro, A., Le, Q. T., \& Park, C. S. (2016). Framework for Integrating Safety into Construction Methods Education through Interactive Virtual Reality. Journal of Professional Issues in Engineering Education and Practice, 142(2), 04015011. https://doi.org/10.1061/(ASCE)El.1943-5541.0000261

[9] pixo2019. (n.d.). The PIXO VR Training Center. Retrieved November 26, 2019, from PIXO VR website: https://pixovr.com/vr-trainingcenter/

[10] Writer, J. D., Content. (n.d.). The History Of Safety In A Construction Environment. Retrieved November 25, 2019, from https://blog.vingapp.com/the-history-of-safety-in-a-construction-environment 